\title{
Effect of the sorting track profile change on the it's occupancy quality at train humping
}

\author{
Konstantin Kornienko ${ }^{1, *}$, and Sergei Bessonenko ${ }^{1}$ \\ ${ }^{1}$ Siberian Transport University, 630049 Novosibirsk, Russia
}

\begin{abstract}
To increase the hump yard capacity, it is necessary to ensure high quality of sorting track occupancy. The purpose of this paper is to study the effect of changing the track profile on the quality of its occupancy. The simulation model developed for occupancy of sorting tracks based on the calculation of the speed of the cut and taking the following into consideration was used for the study: the possibility of starting the cut movement after a stop, errors in operation of the devices in charge of the speed of releasing the cut to the track, the possibility of displacement of the cars when the next cut collides with them. A real profile of the sorting facility track was analyzed as an example of it. It was determined that the profile caused strong effect on the track occupancy quality. The sagging of the profile causes an increase in the probability of collision of the cuts with exceeding the permissible speed. An increase in the up-gradient reduces the range of the run-off distance, which in turn causes an increase in the number of car back-ins. Profile correction will allow increasing the track occupancy quality.
\end{abstract}

\section{Introduction}

Hump yards are one of the most important elements of the transport network, therefore, upgrading of the humps is viewed as one of the main goals of transport development in Russia [1] and in Western Europe [2-5]. This is due to the fact that most of the time required for delivery of goods falls on shunting operations performed at hump yards [6-8]. To reduce this time, it is necessary to increase the hump yard capacity. However, the capacity in the Russian Federation is already 4-5 times higher than in the countries of Western Europe and America [9], so further increase in capacity is possible by increasing the humping speed, introduction of new technologies or reduction of the time spent for performing additional operations.

The third method is most economical. The time is mostly spent for backing-in cars, working with hazardous cargo [10-11], elimination of commercial defects, etc. Reduction of this time is possible with improving the sorting track occupancy quality. The following is understood within the scope of it: minimization of gaps and collision of cuts with the permissible speed [12-13].

To date, a large number of works are devoted to calculation of the sorting track as the main element in terms of quality of its occupancy. Equipping a sorting track with additional

\footnotetext{
*Corresponding author: Kkonstantini@mail.ru
} 
devices is one of the most effective ways to improve the track occupancy quality [13-17]. But this method requires large capital expenses and is complicated in technical implementation and maintenance. The facility braking position also significantly affects the track occupancy quality [18-23]. Incorrect operation of the retarder causes deterioration in the track occupancy quality.

Based on the aforementioned, it can be concluded that there are currently many factors affecting the sorting track occupancy quality, but the effect of the track profile change during operation has not been fully understood. The purpose of this study is to investigate the effect of the track profile on its occupancy quality and the efficiency of profile correction.

\section{Research methods}

The simulating model of track occupancy was used for the study [24-27]. This model considers the possibility of starting the cut movement after a stop, errors in operation of the devices controlling the speed of releasing the cut to the track and operation of the retarder, the possibility of displacement of the cars when the next cut collides with them [25]. Calculation of the speed of the cuts was checked by its comparison to the actual motion speed. Distribution curves were plotted by running this model 100,000 times. The flow of cars and cuts was set with random distribution. The ambient air temperature, wind speed and direction were set for Novosibirsk region, taking into account the correction for the track. The track (Fig. 1) was reviewed within the borders from tangent retarders to insulating joints at the end of the track. The profile survey was performed each 50 meters. The rated values comply with [28-29].

The subject of the study is tracks of the sorting facility. The study object is effect of the track profile on the track occupancy quality.

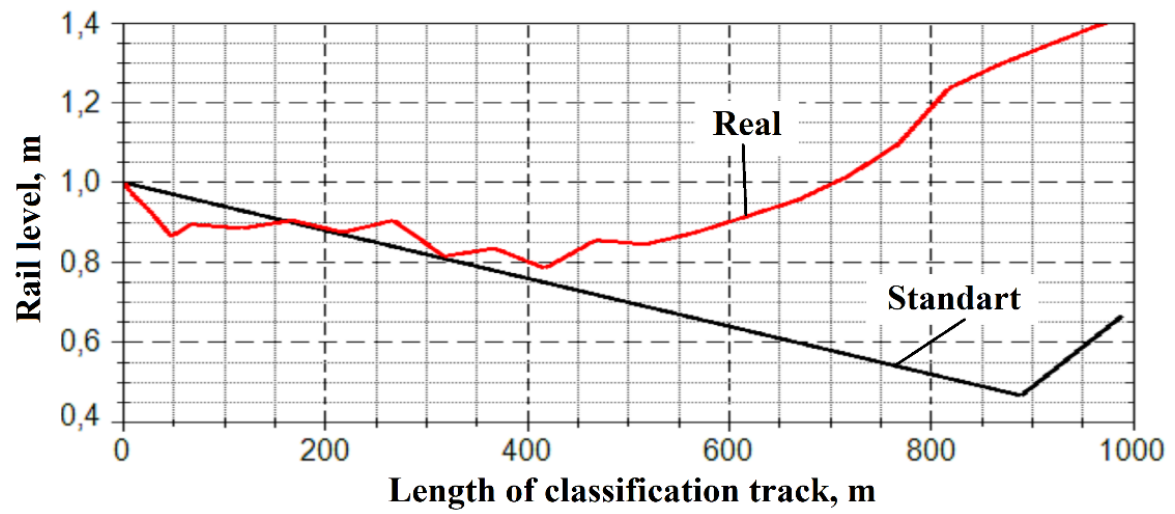

Fig. 1. Track profile of the sorting track.

\section{Effect of the track profile on the cut stop point}

One of the important parameters for traffic safety is calculation of the cut stop point at the sorting track. If this point is defined incorrectly and the next cut is released on track, there is a possibility that the cars will collide at the speed exceeding the permissible value and, consequently, damage cars or cargo. It is also important that the cut can move backwards under the action of gravity, if the cut stops at the up-gradient. The study [25] indicated that the cut full stop point must meet the following two conditions: the speed of the cut at the 
point is equal to zero and the displacement condition is not met including movement in the opposite direction (not taken into consideration today).

In addition to these factors, the track profile also affects the cut stop point, and, consequently, the track profile also affects the range of the cut run at the sorting track [24, 26]. Increase of down-gradient of the track causes an increase in the speed of the cut movement, which causes an increase in the probability of car collision with the increased speed. Increase of the length and steepness of the up-gradient affects the distance of the cut run, since it lowers the cut speed and increases the probability of the cut moving backwards, towards the hump top, and, consequently, increases the gaps, which increases number of backing-out and increases the hump interval, which reduces the hump yard capacity.

Imitation simulation of cut movement on the standard and real profile was performed on the basis of Figure 1. Figure 2 shows distribution curves of the probability of cuts stopping depending on the distance traveled.

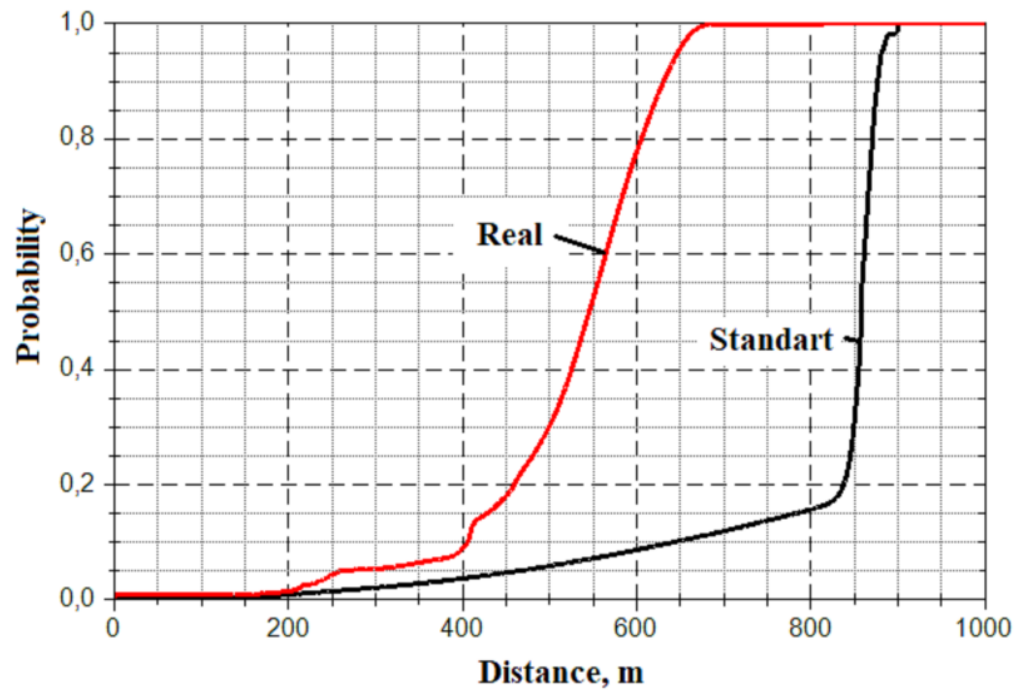

Fig. 2. Distribution of the probability of cars stopping on the track.

The following conclusions can be made on the basis of Figure 2:

- profile changes affects the cut run distance significantly;

- the average cut run range for the standard profile is $813 \mathrm{~m}$ with standard deviation of $137 \mathrm{~m}$;

- the average distance for the real profile is $524 \mathrm{~m}$ with the real of $106 \mathrm{~m}$, therefore, the run distance has been reduced by 289 meters due to the change in the up-gradient.

- None of the cuts released on track with the standard profile has overcome the distance of 840 meters. According to the rules, there is an up-gradient at the end of the track, due to which the cuts roll back. The useful track length is reduced due to this up-gradient, therefore, it is necessary to develop other stop devices at the end of the track to increase the useful track length. 


\section{Effect of the profile on the track occupancy quality}

In connection with displacement of the cut stop point, it can be assumed that the track occupancy level will be below the permissible value. The track occupancy level can be presented with the following formula [30]:

$$
K_{\mathrm{OCC}}^{\mathrm{i}}=\frac{N_{\mathrm{CAR}}^{\mathrm{i}} * L_{\mathrm{CAR}}}{L_{\mathrm{TRACK}}^{\mathrm{i}}}
$$

where $N_{\mathrm{CAR}}^{\mathrm{i}}$ is the number of cars released on track, pcs;

$L_{\mathrm{CAR}}$ - conditional car length, $14 \mathrm{~m}$;

$L_{\text {TRACK }}^{\mathrm{i}}$ - length of the free zone of the sorting track after backing-out, $\mathrm{m}$.

Imitation simulation of the track occupancy with cuts of various length and weight in various conditions was performed for the profile. Results of this simulation, and, in particular, distribution curves of the track occupancy quality for the standard and real profile are presented in Figure 2. This Figure also shows distribution of the track occupancy quality when humping to the free track. Table 1 shows results of the experiment.

Table 1. Experimental results.

\begin{tabular}{|c|c|c|}
\hline Study parameter & Rated profile & $\begin{array}{c}\text { Actual } \\
\text { profile }\end{array}$ \\
\hline Average track quality level & 0.8724 & 0.5775 \\
\hline Average track level coefficient for a free track & 0.8637 & 0.3388 \\
\hline Average number of backing-outs for accumulation of one train & 2.32 & 4.263 \\
\hline Possibility of reverse movement of the cut & 0.079 & 0.314 \\
\hline $\begin{array}{c}\text { Possibility of collision of cuts with exceeding of the collision } \\
\text { speed }\end{array}$ & 0.016 & 0.039 \\
\hline
\end{tabular}

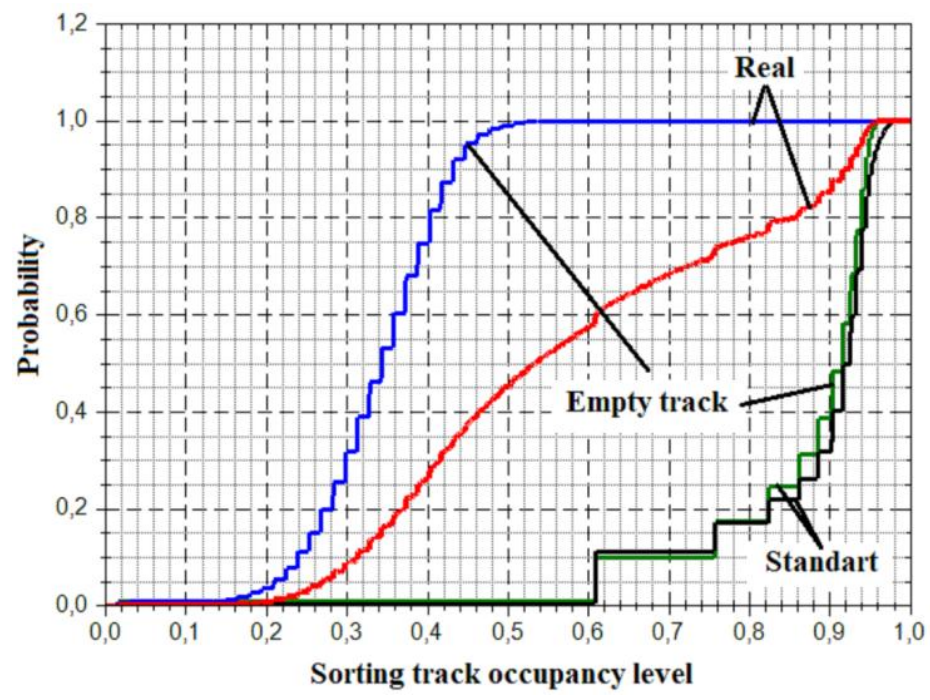

Fig. 3. Track occupancy level distribution. 
The following conclusions can be made on the basis of Table 1 and Figure 3:

- The profile change affects the sorting track occupancy level.

- Experimental results confirm the conclusion that the track occupancy quality for the first breaking up of the train on the free track will be below the permissible value due to the displacement of average cut stop point.

- The average track occupancy level when breaking up to the free track for the real profile is 3 times less than for the standard profile. This means that the standard profile accumulates on an average 36 cars more before the first backing-out.

- [30] indicates that the track occupancy level must be within 0.8 to 1 according to the regulatory documents. This condition is satisfied in most cases for the standard profile, both during humping at the free track and in the course of accumulation of cars on the track, on which cars are already located. This condition is not met in most cases for the track with real profile. When cuts are humping to the free track, the maximum track occupancy level does not exceed 0.5. This means that almost half of the track in this case will not be used until the first backing-outs.

- The average number of backing-outs per one train at the real track is by 2 backingouts more than the one with the standard track. It means that the train accumulation at the real profile requires double time as compared to the standard profile. This causes growth of the hump interval, and, consequently, reduction of the hump yard capacity.

- The probability of reverse movement for the real profile is three time higher than for the standard one. It means that each third cut will not reach the standing cars.

- The probability of collision with increased speed for the real profile is much higher than for the standard one.

- On the basis of the last two points, it can be concluded that the profile significantly reduced the track occupancy quality by increasing gaps and collisions with increased speed.

\section{Conclusion}

Change of down-gradient causes increase in the probability of collision with increased speed between the cut and the cars standing ahead. The change in the up-gradient is the reason for reduction in the distance of the cut run and the useful path length at the first breaking up on the free track. Moreover, after stopping on the up-gradient, the cut starts moving backwards under the effect of the gravity force. When the next cut is released to such track, collision between the cuts with increased speed may take place, unless the first cut has stopped yet. The track occupancy level is less than permissible at tracks with long up-gradient. The tendency of increasing the number of backing-outs for accumulation of one train is also observed when increasing the up-gradient length.

Analysis of real profiles of the sorting track shows that the track occupancy level on many tracks is significantly lower than permissible. This causes shortening of the time period between backing-outs, hence, increasing of the hump interval. Correction of profiles will allow increasing the track occupancy level and reducing the number of backing-outs. The issues of economic efficiency of profile correction or use of other means for increasing the hump yard capacity require further studying.

The authors would like to express their gratitude to the "Operational Work Management" and "Stations and junctions" Department of the Siberian Transport University and employees of the Insk Signaling Division for assistance in writing this article. This study was performed with support of the Novosibirsk Region Government. 


\section{References}

1 Strategija razvitija holdinga RZhD na period do 2030 goda [Development strategy of the Russian Railways for the period until 2030] (16.04.2014). (in Russian)

2 D.M.Z. Islam, S. Ricci, B.L. Nelldal, Eur. Transp. Res. Rev., 8, 18 (2016).

3 P. Mortimer, D.M.Z. Islam, Eur. Transp. Res. Rev., 6, 503 (2014).

4 U. Clausen, R. Voll, Eur. Transp. Res. Rev., 5, 129 (2013).

5 N. Boysen, M. Fliendner, F. Jaehn, E. Pesch, European Journal of Operational Research, 220, 1 - 14 (2012).

6 O.P. Yugrina, Yu.A. Tanayno, Transport of the Urals, 4(51), 83-86 (2016). (in Russian)

7 V.A. Gapanovich, A.N. Shabelnikov, Zheleznodorozhnyj transport [Railway transport], 8 (2010). (in Russian)

8 O.P. Yugrina, S.Yu. Sosnin, Herald of the Ural State University of Railway Transport, 1(33), 84-90 (2017). (in Russian)

9 V.N. Sokolov, Automation, Communication and Informatics, 2 (2011). (in Russian)

10 A.M. Ostrovskiy, A.M. Lisyutin, Scientific papers SWorld, Vol. 2(1), 38-41 (2012). (in Russian)

11 A.F. Borodin, R.V. Ageev, A.S. Krylov, M.B. Sirotich, Zheleznodorozhnyj transport [Railway transport], 7, 20-27 (2010). (in Russian)

12 S.V. Karasev, Thesis of Candidate of technical sciences, Siberian Transport University, Novosibirsk, 2003 (in Russian)

13 S.V. Karasev, V.I. Zhukov, O.V. Kutsenko, Sovershenstvovanie ekspluatacionnoj raboty zheleznyh dorog [Improving the field operation of railways], 119-129 (Novosibirsk, 2002). (In Russian)

14 C. Zhang, Y. Wei, G. Xiao, Z. Wang, J. Fu, Proc. of Second Intern. Conf. on Transportation and Traffic Studies, 285-290 (2000).

15 S. Zarecky, J. Grun, J. Zilka, Transport Problems, Vol. 3(4), 1, 87-95 (2008).

16 V.I. Bobrovskiy, D.N. Kozachenko, N.V. Rogov, Vestnik of Dnepropetrovsk National University of Railway Transport named after V. Lazaryan, 11, 103-111 (2006).

17 D. Kozachenko, V. Bobrovskyi, Y.J. Demchenko, Mod. Transport, 1-11 (2018).

18 V.A. Kobzev, Automation, Communication and Informatics, 10, 30-33 (1996). (in Russian)

19 D.N. Kozachenko, S.V. Grevtsov, T.V. Bolvanovskaya, Vestnik of Dnepropetrovsk National University of Railway Transport named after V. Lazaryan, 4(64), 37-46 (2016).

20 V. Bobrovskyi, D. Kozachenko, A. Dorosh, E. Demchenko, T. Bolvanovska, A. Kolesnik, Transport Problems, Vol. 11(1), 147-155 (2016).

21 C. Worrell, Railway Age, 11, 36-28 (2015).

22 O. Bardas, I. Skovron, Y. Demchenko, A. Dorosh, S. Buriak, Transport Problems, Vol. 12 (1), 151-158 (2017).

23 S.A. Bessonenko, Doctoral thesis, Moscow State University of Railway Engineering, Москва, 2011. (in Russian)

24 E.A. Akhmaev, S.A. Bessonenko, V.V. Borisov, K.I. Kornienko, Transport of the Urals, 4(55), 49-53 (2017). (in Russian)

25 K.I. Kornienko, Transport: Science, Equipment, Management, 11, 36-40 (2017). (in Russian)

26 E.A. Akhmaev, S.A. Bessonenko, V.V. Borisov, K.I. Kornienko, Siberian Transport University Bulletin, 1(40), 13-18 (2017). (In Russian)

27 K.I. Kornienko, Transport of the Urals, 2(57), 35-22 (2018). (in Russian)

28 Yu.A. Mukha, L.B. Tishkov, V.P. Sheykin, et al., Posobie po primeneniju pravil $i$ 
norm proektirovanija sortirovochnyh ustrojstv [Manual on the application of rules and norms for design of assorting works] (Transport, Moscow, 1994). (in Russian)

29 Pravila i normy proektirovanija sortirovochnyh ustrojstv na zheleznyh dorogah kolei $1520 \mathrm{~mm}$ [Rules and norms for the design of sorting works on railways with gauge $1520 \mathrm{~mm}$ ] (Moscow, 2003). (in Russian)

30 A.N. Shabelnikov, V.R. Odikadze, Automation, Communication and Informatics, 3, 9-11 (2009). (in Russian) 